\title{
PENENTUAN PASIEN KEMOTERAPI DENGAN MENGGUNAKAN METODE FORWARD CHAINING
}

\author{
${ }^{1}$ Kurnia Wulan Suci ${ }^{2}$ Budi Sutomo ${ }^{3}$ M. Adie Syaputra \\ ${ }^{1}$ Kurnia Wulan Suci, STMIK Dharma Wacana, ulin78974@gmail.com \\ ${ }^{2}$ Budi Sutomo, STMIK Dharma Wacana, budi.atmel@gmail.com \\ ${ }^{3}$ M. Adie Syaputra, STMIK Dharma Wacana, m4adie@gmail.com
}

\begin{abstract}
Abstrak
Penulisan ini menjelaskan tentang penentuan pasien kemoterapi dengan menggunakan metode forward chaining, serta metode OOSE sebagai tahapan tahapan apa saja yang akan dilakukan, dan pemrograman ini berbasis website. Kemoterapi merupakan cara pengobatan tumor dengan memberikan obat pembasmi sel kanker, yang diminum ataupun diinfuskan ke pembuluh darah. Obat kemoterapi akan menyebar ke seluruh jaringan tubuh, dan dapat membasmi sel-sel kanker yang sudah menyebar luas di seluruh tubuh. Ketika pasien akan di lakukan kemoterapi, pasien harus memenuhi beberapa syarat tertentu. Pengambilan keputusan layak atau tidaknya pasien untuk di kemoterapi harus melalui prosedur yang panjang dan lama. Oleh karena itu diperlukan adanya sistem yang dapat membantu dokter dalam pengambilan keputusan kemoterapi agar lebih cepat. Metode Forward Chaining memiliki konsep logika yang sama dengan dokter pada saat pengambilan keputusan penentuan pasien kemoterapi karena berbasis if-then. Untuk memperoleh kesimpulan digunakan metode forward chaining untuk menentukan pasien layak atau tidaknya untuk di kemoterapi, tanpa harus menunggu dokter untuk menentukan pasien layak atau tidaknya untuk dikemoterapi.
\end{abstract}

\section{Kata Kunci : Kemoterapi, Forward Chaining}

\section{Pendahuluan}

Saat ini teknologi sangat dibutuhkan untuk membantu pelayanan kesehatan terutama pada pasien kanker yang saat ini menjadi pusat atau penyebab kematian utama. Pengendalian penyakit kanker merupakan salah satu komitmen global, regional maupun nasional. Upaya yang dilakukan bermula dari pencegahan, deteksi dini (skrining), diagnosis dan pengobatan. Salah satu pengobatan dari penyakit kanker adalah pengobatan dengan kemoterapi.

Kemoterapi merupakan cara pengobatan tumor dengan memberikan obat pembasmi sel kanker, yang diminum ataupun diinfuskan ke pembuluh darah. Obat kemoterapi akan menyebar ke seluruh jaringan tubuh, dan dapat membasmi sel-sel kanker yang sudah menyebar luas di seluruh tubuh (Handayani, 2015). Ketika pasien akan di lakukan kemoterapi, pasien kemoterapi harus memenuhi beberapa syarat tertentu. Pengambilan keputusan layak atau tidaknya pasien untuk di kemoterapi harus melalui prosedur yang panjang.

Metode Forward Chaining memiliki konsep logika yang sama dengan dokter pada saat pengambilan keputusan penentuan pasien kemoterapi karena berbasis if-then. Forward Chaining adalah teknik pencarian yang dimulai dengan fakta yang diketahui, kemudian mencocokkan fakta-fakta tersebut dengan bagian IF dari Rules IF-THEN. Bila ada fakta yang cocok dengan bagian IF, maka rule tersebut dieksekusi. Bila sebuah rule dieksekusi, maka sebuah fakta baru (bagian THEN) ditambahkan kedalam database. Untuk memperoleh kesimpulan digunakan metode forward chaining untuk menentukan pasien layak atau tidaknya untuk di kemoterapi, tanpa harus menunggu dokter untuk menentukan pasien layak atau tidaknya untuk dikemoterapi.

\section{Metode Penelitian}

Metode penelitian yang digunakan dalam menentukan pasien layak atau tidaknya untuk di kemoterapi adalah metode forward chaining. Forward chaining merupakan suatu stategi pengambilan keputusan yang dimulai dari fakta menuju kesimpulan akhir. Dimana salah satu aspek penting dari perolehan fakta adalah dengan menanyakan pertanyaan yang benar. Pertanyaan benar akan diajukan, dan menghasilkan efisiensi dalam menentukan jawaban yang benar. Syarat yang nyata adalah sistem pakar hanya akan menanyakan pertanyaan yang berhubungan dengan hipotesis kemudian dicoba untuk dibuktikan. 
Berikut adalah aturan proses dari aplikasi Penentuan Pasien Kemoterapi Dengan Menggunakan Metode Forward Chaining.

1. Tabel Pemeriksaan Logika Forward Chaining

\begin{tabular}{|c|c|}
\hline KODE & PEMERIKSAAN \\
\hline A & Leokosit \\
\hline $\mathrm{A}_{1}$ & Apakah Leokosit Bemilai $<5$ ? \\
\hline $\mathrm{A}_{2}$ & Apakah Leokosit Bemilai $>5<10$ ? \\
\hline $\mathrm{A}_{3}$ & Apakah Leokosit Bemilai>10? \\
\hline B & Hemoglobin \\
\hline $\mathrm{B}_{1}$ & Apakah Hemoglobin Bemilai $<10$ ? \\
\hline $\mathrm{B}_{2}$ & Apakah Hemoglobin Bemilai $>10<16$ ? \\
\hline $\mathrm{B}_{3}$ & Apakah Hemoglobin Bemilai >16? \\
\hline $\mathrm{C}$ & Trombosit \\
\hline $\mathrm{C}_{1}$ & Apakah Trombosit Bemilai $<150$ ? \\
\hline $\mathrm{C}_{2}$ & Apakah Trombosit Bemilai $>150<450$ ? \\
\hline $\mathrm{C}_{3}$ & Apakah Trombosit Bemilai $>450$ ? \\
\hline $\mathrm{D}$ & Sgot \\
\hline $\mathrm{D}_{1}$ & Apakah Sgot Bemilai $<102$ \\
\hline $\mathrm{D}_{2}$ & Apakah Sgot Bemilai $>10<31$ ? \\
\hline $\mathrm{D}_{3}$ & Apakah Sgot Bemilai $>312$ \\
\hline $\mathrm{E}$ & Sgpt \\
\hline$E_{1}$ & Apakah Sgpt Bemilai $<10$ ? \\
\hline $\mathrm{E}_{2}$ & Apakah Sgpt Bemilai $>10<31$ ? \\
\hline$E_{3}$ & Apakah Sgpt Bemilai >31 ? \\
\hline $\mathrm{F}$ & Albumin \\
\hline $\mathrm{F}_{1}$ & Apakah Albumin Bemilai >2.5 ? \\
\hline $\mathrm{F}_{2}$ & Apakah Albumin Bemilai $>2.5<5.2$ ? \\
\hline$F_{3}$ & Apakah Albumin Bemilai $>5,2$ ? \\
\hline G & Glukosa Darah Sewaktu \\
\hline $\mathrm{G}_{1}$ & Apakah Glukosa Sewaktu Bemilai >20? \\
\hline $\mathrm{G}_{2}$ & Apakah Glukosa Sewaktu Bemilai $>90<140$ ? \\
\hline $\mathrm{G}_{3}$ & Apakah Glukosa Sewaktu Bemilai >140? \\
\hline $\mathrm{H}$ & Ureum \\
\hline $\mathrm{H}_{1}$ & Apakah Ureum Bemilai $>15$ ? \\
\hline $\mathrm{H}_{2}$ & Apakah Ureum Bemilai $>15<40$ ? \\
\hline $\mathrm{H}_{3}$ & Apakah Ureum Bemilai $>40$ ? \\
\hline I & Kreatinin \\
\hline $\mathrm{I}_{1}$ & Apakah Kreatinin Bemilai >0.6? \\
\hline $\mathrm{I}_{2}$ & Apakah Kreatinin Bemilai $>0.6<1.1$ ? \\
\hline $\mathrm{I}_{3}$ & Apakah Kreatinin Bemilai $>1.1$ ? \\
\hline $\mathrm{P}_{1}$ & Perbaiakan Kurang Dari 2 \\
\hline $\mathrm{P}_{2}$ & Perbaiakan Lebih Dari 2 \\
\hline
\end{tabular}

2. Tabel Solusi Logika Forward Chaining

\begin{tabular}{|l|l|}
\hline KODE & SOLUSI \\
\hline PA & Perbaiakan Leokosit \\
\hline PB & Perbaiakan Hemoglobin \\
\hline PC & Perbaiakan Trombosit \\
\hline PD & Perbaiakan Sgot \\
\hline PE & Perbaiakan Sgpt \\
\hline PF & Perbaiakan Albumin \\
\hline PG & Perbaiakan Glukosa Darah Sewaktu \\
\hline PH & Perbaiakan Ureum \\
\hline PI & Perbaiakan Kreatinin \\
\hline RK & Rekomendasi Kemoterapi \\
\hline ACC & ACC Kemoterapi \\
\hline KB & Kemoterapi Bersyarat \\
\hline TK & Tunda Kemoterapi \\
\hline
\end{tabular}

3. Rule Pada Pakar

Fakta - Fakta Atau Aturan -Aturan Yang Digunakan Dalam Sistem Pakar Ini Adalah :

- Rule 1 : If Lekosit And Leokosit Bernilai <5 ? Then Perbaikan Leokosit

- Rule 2 : If Lekosit And Leokosit Bernilai $>5<10$ ? Then Rekomendasi Kemoterapi

- Rule 3 : If Lekosit And Leokosit Bernilai >10 ? Then Rekomendasi Kemoterapi
- Rule 4 : If Hemoglobin And Hemoglobin Bernilai <10 ? Then Perbaikan Hemoglobin

- Rule 5 : If Hemoglobin And Hemoglobin Bernilai $>10<16$ ? Then Rekomendasi Kemoterapi

- Rule 6 : If Hemoglobin And Hemoglobin Bernilai >16 ? Then Rekomendasi Kemoterapi

- Rule 7 : If Trombosit And Trombosit Bernilai <150 ? Then Perbaikan Trombosit

- Rule 8 : If Trombosit And Trombosit Bernilai $>150<450$ ? Then Rekomendasi Kemoterapi

- Rule 9 : If Trombosit And Trombosit Bernilai >450 ? Then Rekomendasi Kemoterapi

- Rule 10 : If Sgot And Sgot Bernilai <10 ? Then Perbaikan Sgot

- Rule 11 : If Sgot And Sgot Bernilai $>10<31$ ? Then Rekomendasi Kemoterapi

- Rule 12 : If Sgot And Sgot Bernilai > 31 ? Then Rekomendasi Kemoterapi

- Rule 13 : If Sgpt And Sgpt Bernilai <10 ? Then Perbaikan Sgpt

- Rule 14 : If Sgpt And Sgpt Bernilai $>10<31$ ? Then Rekomendasi Kemoterapi

- Rule 15 : If Sgpt And Sgpt Bernilai >31 ? Then Rekomendasi Kemoterapi

- Rule 16 : If Albumin And Albumin Bernilai > 2.5 ? Then Perbaikan Albumin

- Rule 17 : If Albumin And Albumin Bernilai $>2.5<5.2$ ? Then Rekomendasi Kemoterapi

- Rule 18 : If Albumin And Albumin Bernilai >5.2 ? Then Rekomendasi Kemoterapi

- Rule 19 : If Glukosa Sewaktu And Glukosa Sewaktu Bernilai >90 ? Then Perbaikan Glukosa Sewaktu

- Rule 20 : If Glukosa Sewaktu And Glukosa Sewaktu Bernilai $>90<140$ ? Then Rekomendasi Kemoterapi

- Rule 21 : If Glukosa Sewaktu And Glukosa Sewaktu Bernilai >140 ?Then Rekomendasi Kemoterapi

- Rule 22 : If Ureum And Ureum Bernilai $>15$ ? Then Perbaikan Ureum

- Rule 23 : If Ureum And Ureum Bernilai $>15<40$ ? Then Rekomendasi Kemoterapi

- Rule 24 : If Ureum And Ureum Bernilai $>40$ ? Then Rekomendasi Kemoterapi

- Rule 25 : If Kreatinin And Kreatinin Bernilai >0.6 ? Then Perbaikan Kreatinin 
- Rule 26 : If Kreatinin And Kreatinin Bernilai $>0.6<1.1$ ? Then Rekomendasi Kemoterapi

- Rule 27 : If Kreatinin And Kreatinin Bernilai >1.1? Then Rekomendasi Kemoterapi

- Rule 28 : If Pemeriksaan And Lekosit, Hemoglobin, Trombosit, SGOT, SGPT,

- Albumin, Gulukosa Sewaktu, Ureum, Kreatinin And Rekomendasi Kemoterapi Then Acc Kemoterapi

- Rule 29 : If Pemeriksaan And Lekosit, Hemoglobin, Trombosit, SGOT, SGPT,

- Albumin, Gulukosa Sewaktu, Ureum, Kreatinin And Perbaikan Kurang Dari 2 Then Kemoterapi Bersyarat

- Rule 30 : If Pemeriksaan And Lekosit, Hemoglobin, Trombosit, SGOT, SGPT,

- Albumin, Gulukosa Sewaktu, Ureum, Kreatinin And Perbaikan Lebih Dari 2 Then Tunda Kemoterapi

\section{Rule Simplification}

- Rule 1 : If A And A1 Then PA

- Rule 2 : If A And A2 Then RK

- Rule 3 : If A And A3Then RK

- Rule 4 : If B And B1 Then PB

- Rule 5 : If B And B2 Then RK

- Rule 6 : If B And B3 Then RK

- Rule 7 : If C And C1 Then PC

- Rule 8 : If C And C2 Then RK

- Rule 9 : If C And C3 Then RK

- Rule 10 : If D And D1 Then PD

- Rule 11 : If D And D2 Then RK

- Rule 12 : If D And D3 Then RK

- Rule 13 : If E And E1 Then PE

- Rule 14 : If E And E2 Then RK

- Rule 15 : If E And E3 Then RK

- Rule 16 : If F And F1 Then PF

- Rule 17 : If F And F2 Then RK

- Rule 18 : If F And F3 Then RK

- Rule 19 : If G And G1 Then PG

- Rule 20 : If G And G2 Then RK

- Rule 21 : If G And G3 Then RK

- Rule 22 : If H And H1 Then PH

- Rule 23 : If H And H2 Then RK

- Rule 24 : If H And H3 Then RK

- Rule 25 : If I And I1 Then PI

- Rule 26 : If I And I2 Then RK

- Rule 27 : If I And I3 Then RK

- Rule 28 : If P And A,B,C,D,E,F,G,H,I And RK Then ACC

- Rule 29 : If P And A,B,C,D,E,F,G,H,I And P1Then KB
- Rule 30 : If P And A,B,C,D,E,F,G,H,I And P2 Then TK

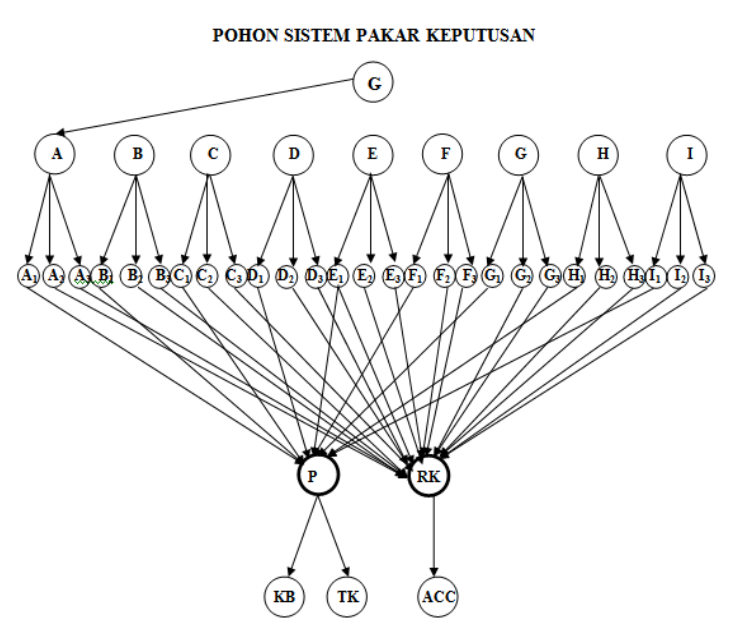

Hasil dan Pembahasan

Berikut adalah contoh permasalahan yang harus di selesaikan dengan menggunkan metode forward chaining

1. Tabel contoh kasus logika forward chaining

\begin{tabular}{|c|l|c|}
\hline NO & \multicolumn{1}{|c|}{ NAMA LAB } & HASIL \\
\hline 1 & Leokosit & 4.75 \\
\hline 2 & Hemoglobin & 10.7 \\
\hline 3 & Trombosit & 257 \\
\hline 4 & Sgot & 13.7 \\
\hline 5 & Sgpt & 12.8 \\
\hline 6 & Albumin & 3.34 \\
\hline 7 & Glukosa Darah Sewaktu & 97.0 \\
\hline 8 & Ureum & 18.0 \\
\hline 9 & Kreatinin & 0.89 \\
\hline
\end{tabular}

Berikut penjabaran dari kasus diatas :

1. Menentukan rule berdasarkan table aturan di atas

Rule 1 : If Lekosit And Leokosit Bernilai <5 ? Then Perbaikan Leokosit

Rule 2 : If Hemoglobin And Hemoglobin Bernilai $10<16$ ? Then Rekomendasi Kemoterapi

Rule 3 : If Trombosit And Trombosit Bernilai $>150<450$ ? Then Rekomendasi Kemoterapi

Rule 4 : If Sgot And Sgot Bernilai $>10<31$ ? Then Rekomendasi Kemoterapi

Rule 5 : If Sgpt And Sgpt Bernilai $>10<31$ ? Then Rekomendasi Kemoterapi 
Rule 6 : If Albumin And Albumin Bernilai $>2.5<5.2$ ? Then Rekomendasi Kemoterapi

Rule 7 : If Glukosa Sewaktu And Glukosa Sewaktu Bernilai $>90<140$ ? Then Rekomendasi Kemoterapi

Rule 8 : If Ureum And Ureum Bernilai $>15<40$ ? Then Rekomendasi Kemoterapi

Rule 9 : If Kreatinin And Kreatinin Bernilai $>0.6<1.1$ ? Then Rekomendasi Kemoterapi

Rule 10 : If Pemeriksaan And Lekosit, Hemoglobin,Trombosit, SGOT, SGPT, Albumin, Gulukosa Sewaktu, Ureum, Kreatinin And Perbaikan Kurang Dari 2 Then Kemoterapi Bersyarat

2. Membuat Rule Simplification : If A And A1 Then PA

Rule 2 : If B And B2 Then RK

Rule 3 : If $C$ And $C 2$ Then RK

Rule 4 : If D And D2 Then RK

Rule 5 : If E And E2 Then RK

Rule $6 \quad$ : If $F$ And F2 Then RK

Rule 7 : If G And G2 Then RK

Rule $8 \quad$ : If $\mathrm{H}$ And $\mathrm{H} 2$ Then RK

Rule 9 : If I And I2 Then RK

Rule 10 : If P And A,B,C,D,E,F,G,H,I And P1 Then KB

3. Membuat Pohon Sistem Pakar Keputusan POHON SISTEM PAKAR KEPUTUSAN

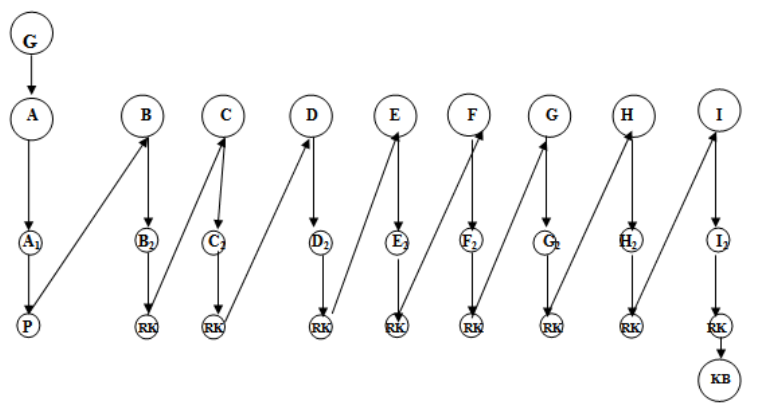

\section{Kesimpulan}

Dapat disimpulkan bahwa dengan menerapkan metode Forward chaining memiliki akurasi hasil pencapain sebesar $99 \%$ dari hasil keputusan dokter, jadi metode ini mampu diterapkan di dalam penentuan pasien kemoterapi.

\section{Daftar Pustaka}

D. W. Handayani. (2015). Farmakologi Jilid 1, Yogyakarta: Deepublish.

A. Prastowo. (2017). Menyusun Rencana Pelaksanaan Pembelajaran (RPP) Tematik Terpadu, Jakarta: Kencana.

P. Hidayatullah and J. K. Kawistara. (2015). Pemrograman Web, Bandung: Informatika Bandung.

A. B. Hikmah. (2015). Cara Cepat Membangun Website Dari Nol, Yogyakarta: Andi.

Y. Purbadian. (2015). Aplikasi Penjualan Web Base Dengan PHP Untuk Panduan Skripsi, Jawa Barat: CV. Asfa Solution. 